\title{
INFLUENCE OF STRUCTURE ON FORMABILITY OF STAINLESS STEELS USED AT PRODUCTION OF EXHAUST COMPONENTS
}

\author{
${ }^{1}$ Jiří SOBOTKA, ${ }^{1}$ Pavel SOLFRONK, ${ }^{1}$ Martin ŠVEC, ${ }^{1}$ David KOREČEK \\ ${ }^{1} T U L$ - Technical University of Liberec, Liberec, Czech Republic, EU, \\ iiri.sobotka@tul.cz, pavel.solfonk@tul.cz, martin.svec@tul.cz, david.korecek@tul.cz
}

https://doi.org/10.37904/metal.2021.4107

\begin{abstract}
Stainless steels are nowadays used in a wide range of industrial products. One example of their utilization in the industrial practice represents production of the exhaust systems components in the automotive industry. Corrosion-resistant materials intended to be processed by the forming technologies generally reveal very good deformation properties and high mechanical values as well. These properties are given mainly due to the high content of alloying elements, stability of the chemical composition and production technology. The submitted paper evaluates the influence of structure on the formability of two stainless steels 1.4301 (designation acc. to EN 10028-7-2016) used for production the exhaust system components. Each of the tested stainless steels is supplied by a different manufacturer. Despite the declared identical chemical composition and the same mechanical properties, one of the tested materials showed quite high level of scrap production. As a critical point of the production there was identified the cutting operation in combination with the subsequent expansion of the cut hole. During this operation, a massive crack occurred in one of the tested materials in the circumferential part of flange. Moreover, the crack always occurred in the identical location of the product. Own formability evaluation was assessed by means of a static tensile test and structural analysis performed on a TESCAN MIRA 3 electron microscope. In addition to these tests, a hole expansion test with different adjustment of cutting clearance was also performed. Based upon the measured data, there were formulated conclusions regarding the causes of cracking in the case of one tested corrosion-resistant material designed for production the exhaust components.
\end{abstract}

Keywords: Stainless Steel, Structural Analysis, Formability, Electron Microscope, Hole Expansion Test

\section{INTRODUCTION}

In the production of stainless materials, advanced technological procedures are used to declare their exact chemical composition and mechanical properties. Excellent formability, high strain hardening exponent and stability of the mechanical properties predetermine these materials for the production of parts using the metal forming technologies [1,2]. However, during forming are in most cases used various combinations of individual technological operations and processes, which reduce the plastic properties of processed material - thus can negatively affect the part production process. One of these operations that significantly affects the plastic abilities of the material is the cutting technology, where around the cutting edge can be determined a fatal depletion of plastic properties in combination with the microcracks occurrence on the cutting edge. Both of these factors can cause problems within any subsequent metal forming operations. One of the common combinations of such forming technologies represents a cutting with subsequent expansion of the given cut hole $[3,4,5]$. The submitted paper deals with the possible causes of cracking in the case of corrosion-resistant material at production components for exhaust systems, where technologies mentioned above are combined. For production is used a stainless steel material 1.4301 (designation acc. to EN 10028-7-2016) with a thickness of $1 \mathrm{~mm}$, which is supplied by two manufacturers. The shape of manufactured part (to be specific - shape of the expanded hole) together with the critical area of fracture can be seen in Figure 1. 


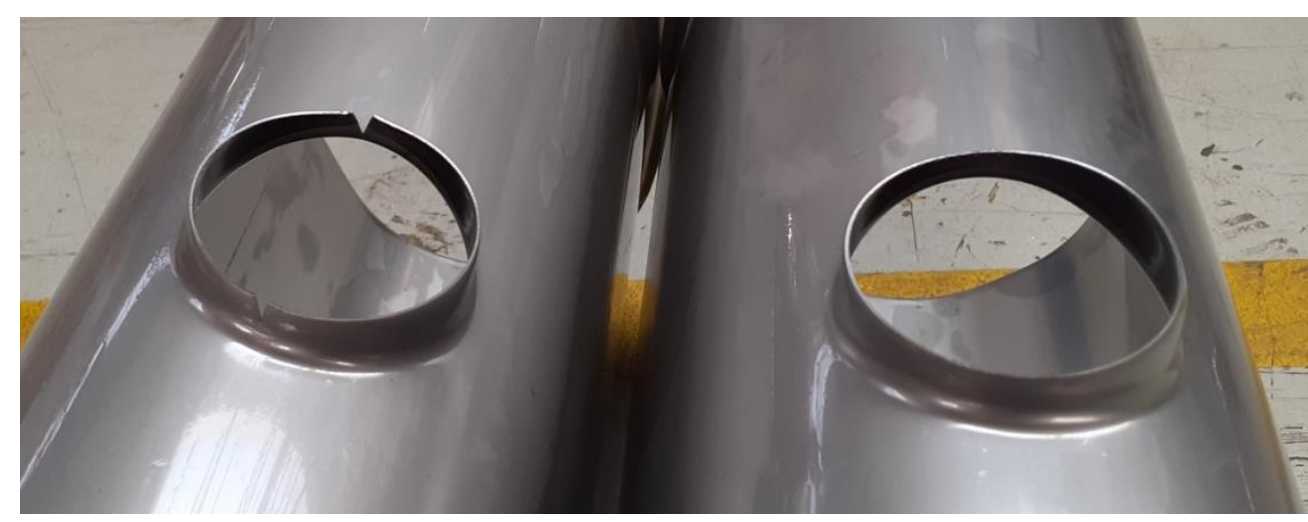

Figure 1 Geometry of the tested parts (detail of expanded holes with/without fracture)

The manufacturers of comparing materials declare both mechanical values and chemical composition. Despite the fact that both materials fulfil requirements given by the relevant standard, there is a significantly higher scrap rate during production in the case of one manufacturer than in the other one. For comparison purposes, both tested materials were marked as 1.4301 - OK and 1.4301 - NOK.

\section{ANALYSYS OF CRACKING CAUSES}

As part of the research about possible causes of cracking for the given product, there were performed the following tests and analysis: static tensile test to determine the basic mechanical properties, hole expansion test (technological test - so-called Marciniak test), analysis of the chemical composition and structural analysis. Such selection aroused from the basic mechanical and structural analysis of materials $[6,7]$.

\subsection{Static tensile test}

Basic mechanical values of tested materials were determined by means of the static tensile test - always from a set of 5 specimens. Testing specimens were cut in directions $0^{\circ}$ and $90^{\circ}$ with respect to the rolling direction. The shape and dimensions of testing specimens were chosen in acc. with the standard ČSN EN ISO 6892-1. Testing specimens of both tested materials were prepared by shearing followed by grinding of cut surfaces. Methodology and evaluation of the static tensile test was done again in accordance with the above-mentioned standard ČSN EN ISO 6892-1. The static tensile test was performed on a TIRA Test 2300 machine using software Labtest 4.9 for processing the measured data and evaluation the basic mechanical characteristics (proof yield strength $R_{p 0.2}$, ultimate strength $R_{m}$, uniform ductility $A_{g}$ and total ductility $A_{80 \mathrm{~mm}}$ ). The values of material characteristics determined in the way described above are summarized in Table 1, where are given the mean values of monitored characteristics (averages) as well as standard deviations. Characteristic graphs (engineering stress-strain curves) both for all tested materials and used direction are shown in Figure 2.

Table 1 Mechanical properties of tested materials 1.4301 (OK and NOK), thickness $t_{0}=1 \mathrm{~mm}$

\begin{tabular}{|c|c|c|c|c|c|}
\hline \multicolumn{2}{|c|}{ Specimen and rolling direction } & $\begin{array}{c}\boldsymbol{R}_{\mathrm{p0}, 2} \\
(\mathrm{MPa})\end{array}$ & $\begin{array}{c}\boldsymbol{R}_{\mathrm{m}} \\
(\mathrm{MPa})\end{array}$ & $\begin{array}{c}\boldsymbol{A}_{\mathrm{g}} \\
\text { (\%) }\end{array}$ & $\begin{array}{c}\boldsymbol{A}_{80 \mathrm{~mm}} \\
(\%)\end{array}$ \\
\hline \multirow{2}{*}{$\mathbf{1 . 4 3 0 1}-\mathbf{O K}$} & $\mathbf{0}^{\circ}$ & $301.5 \pm 0.9$ & $668.0 \pm 1.8$ & $46.4 \pm 0.5$ & $53.2 \pm 0.5$ \\
\cline { 2 - 6 } & $\mathbf{9 0}^{\circ}$ & $290.0 \pm 4.0$ & $634.5 \pm 1.9$ & $53.0 \pm 0.9$ & $60.0 \pm 0.5$ \\
\hline \multirow{2}{*}{$\mathbf{1 . 4 3 0 1}-$ NOK } & $\mathbf{0}^{\circ}$ & $293.5 \pm 0.9$ & $666.5 \pm 1.9$ & $47.5 \pm 0.4$ & $52.6 \pm 0.4$ \\
\cline { 2 - 6 } & $\mathbf{9 0}^{\circ}$ & $286.5 \pm 3.5$ & $641.0 \pm 2.1$ & $54.4 \pm 0.7$ & $58.8 \pm 0.7$ \\
\hline
\end{tabular}




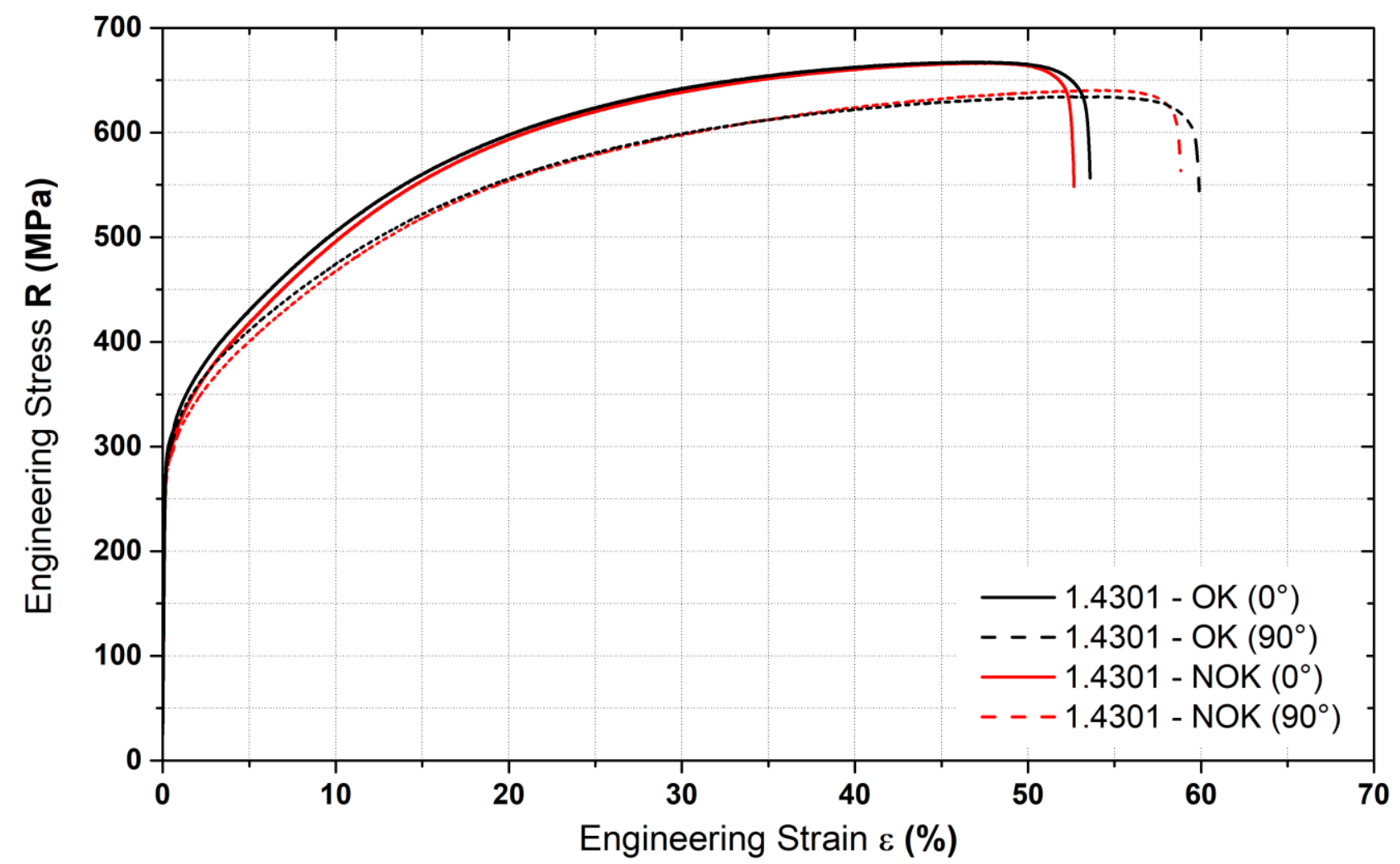

Figure 2 Stress-strain curves from the static tensile test - material 1.4301 (OK and NOK)

\subsection{Hole expansion test (Marciniak test)}

The test methodology and evaluation were chosen regarding the standard ISO/DIS 12004-2. The specimen with a cut hole having diameter $20 \mathrm{~mm}$ was expanded with a flat punch of diameter $100 \mathrm{~mm}$ until a crack was formed in the area of cut edge. The radius of punch drawing edge R10 was chosen in accordance with standard ISO/DIS 12004-2. The principle of the hole expansion test is schematically shown in Figure 3. Three different cutting clearances were chosen for the test - they were as following: $1 \%, 8 \%$ and $16 \%$ with respect to the initial thickness to of tested material. These magnitudes of used cutting clearances were applied based upon the measurement the real cutting clearances of the tool that is used to manufacture components of the exhaust systems. From the measured values of hole diameters at the beginning and at the end of the test, the tangential strain (tangential fracture strain) was subsequently calculated according to equation (1), which can serve as a numerical explanation of cutting technology influence on the subsequent plastic properties of tested materials. The values of such tangential strain for both tested materials (1.4301 - OK and NOK), determined as described above, were processed in Table 2, where the mean values of monitored characteristics (averages) and the standard deviations always from 5 measurements are given. The own courses of tangential strain in dependence on the used cutting clearances for both tested materials are shown in Figure 4.

$\varphi_{t}=\ln \left(\frac{D}{D_{0}}\right)$

where:
$\varphi_{t}$ - the tangential strain (1)
$D$ - the final diameter $(\mathrm{mm})$
$D_{0}$ - the initial diameter $(\mathrm{mm})$ 

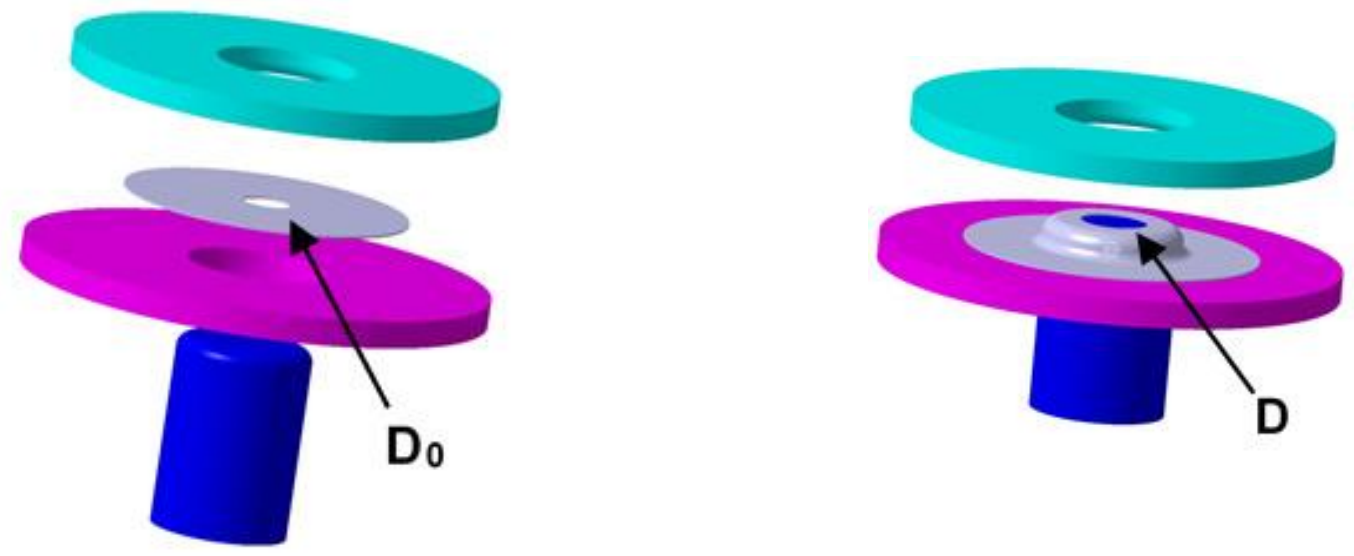

Figure 3 Principle of the hole expansion test (Marciniak test) - before and after test

Table 2 Values of tangential strain for both tested materials $1.4301\left(\mathrm{t}_{0}=1 \mathrm{~mm}\right)$

\begin{tabular}{|c|c|c|c|}
\hline \multirow{2}{*}{ Tested material } & \multicolumn{3}{|c|}{ Tangential strain $\varphi_{t}(\mathbf{1})$} \\
\cline { 2 - 4 } & $\mathbf{m}_{\mathbf{s}}=\mathbf{1} \% \mathbf{t}_{\mathbf{0}}$ & $\mathbf{m}_{\mathbf{s}}=\mathbf{8} \% \mathbf{t}_{\mathbf{0}}$ & $\mathbf{m}_{\mathbf{s}}=\mathbf{1 6} \% \mathbf{t}_{\mathbf{0}}$ \\
\hline $1.4301-\mathrm{OK}$ & $0.441 \pm 0.012$ & $0.551 \pm 0.013$ & $0.564 \pm 0.016$ \\
\hline $1.4301-\mathrm{NOK}$ & $0.404 \pm 0.020$ & $0.473 \pm 0.021$ & $0.556 \pm 0.024$ \\
\hline
\end{tabular}

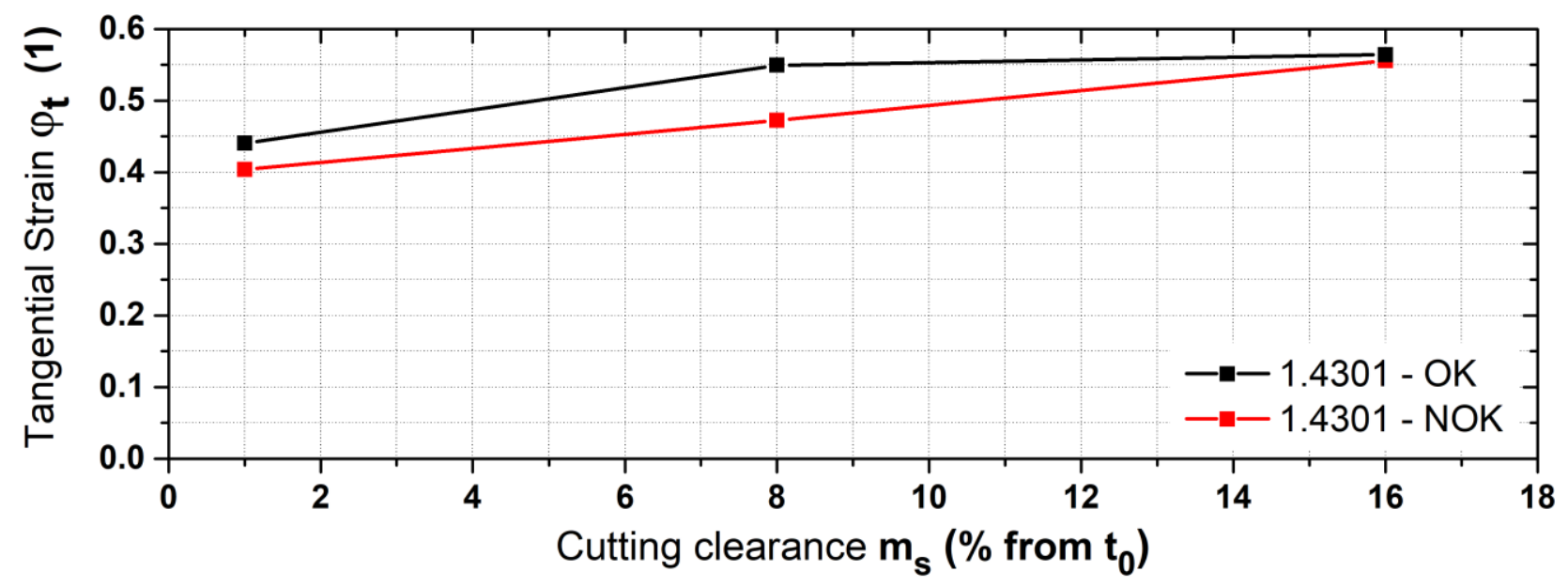

Figure 4 Tangential strain $\varphi_{t} v s$. cutting clearances $m_{s}$ for both tested material

\subsection{Chemical composition analysis}

Chemical composition analysis was performed on a Bruker-Quantron spark-optical emission spectrometer labelled as Q4 Tasman. Such analysis was determined based on five measurements for each tested material (1.4301 - OK and 1.4301 - NOK). Results are summarized in Table 3, with the average values.

Table 3 Chemical composition of tested materials (1.4301 - OK and $1.4301-$ NOK)

\begin{tabular}{|c|c|c|c|c|c|c|c|c|c|c|}
\hline \multirow{2}{*}{ Specimen } & \multicolumn{10}{|c|}{ Chemical element [wt\%] } \\
\cline { 2 - 13 } & $\mathbf{C}$ & $\mathbf{S i}$ & $\mathbf{V}$ & $\mathbf{C r}$ & $\mathbf{M n}$ & $\mathbf{F e}$ & $\mathbf{N i}$ & $\mathbf{C u}$ & $\mathbf{N b}$ & Mo \\
\hline OK & 0.043 & 0.260 & 0.090 & 18.201 & 1.755 & 70.975 & 8.065 & 0.310 & 0.009 & 0.345 \\
\hline NOK & 0.051 & 0.375 & 0.101 & 17.835 & 1.325 & 71.555 & 7.945 & 0.545 & 0.009 & 0.302 \\
\hline
\end{tabular}




\subsection{Structural analysis}

Structural analysis was performed on a scanning electron microscope TESCAN MIRA 3. During the analysis of possible cracking causes of material 1.4301 - NOK, men grain size and ratio of the individual phases (austenite and ferrite) in the structure were analysed for both tested materials. An example of the structural analysis results can be seen in Figure $\mathbf{5}$ (mean grain size) and Figure $\mathbf{6}$ (ratio of the individual phases).

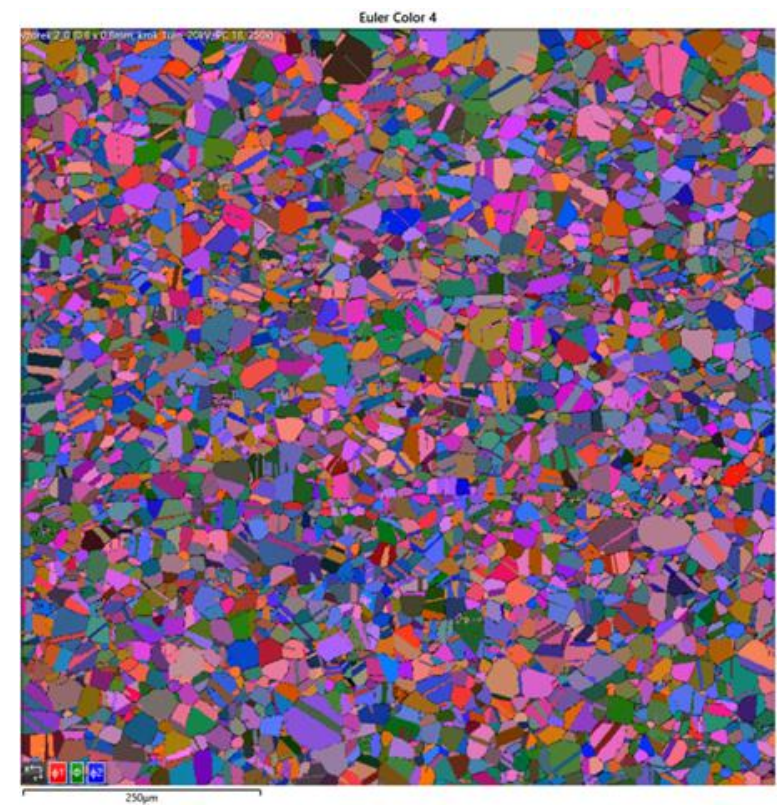

$1.4301-$ OK

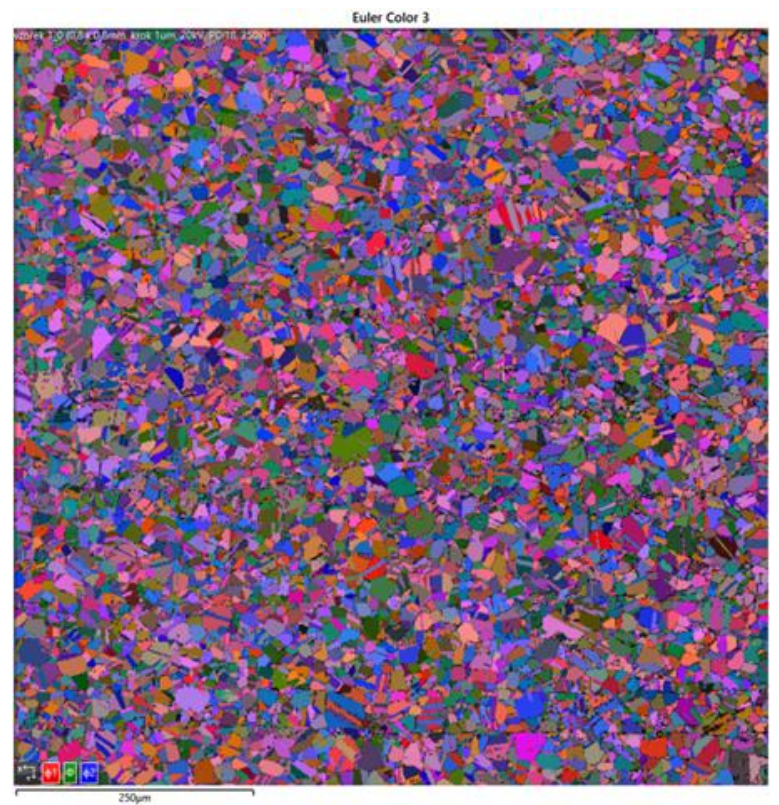

$1.4301-$ NOK

Figure 5 Structural analysis - mean grain size

From the grain size analysis is evident, that material labelled as 1.4301 - NOK has a mean grain size ECD equal to magnitude $14.95 \mu \mathrm{m}$. Material labelled as 1.4301 - OK has a mean grain size ECD equal to magnitude $17.1 \mu \mathrm{m}$. As a basic structural phase for both tested material there is austenitic phase. Residual phase consists of ferritic phase with portion about $3 \%$ in the case of 1.4301 - NOK and cca $0.5 \%$ for material $1.4301-$ OK.

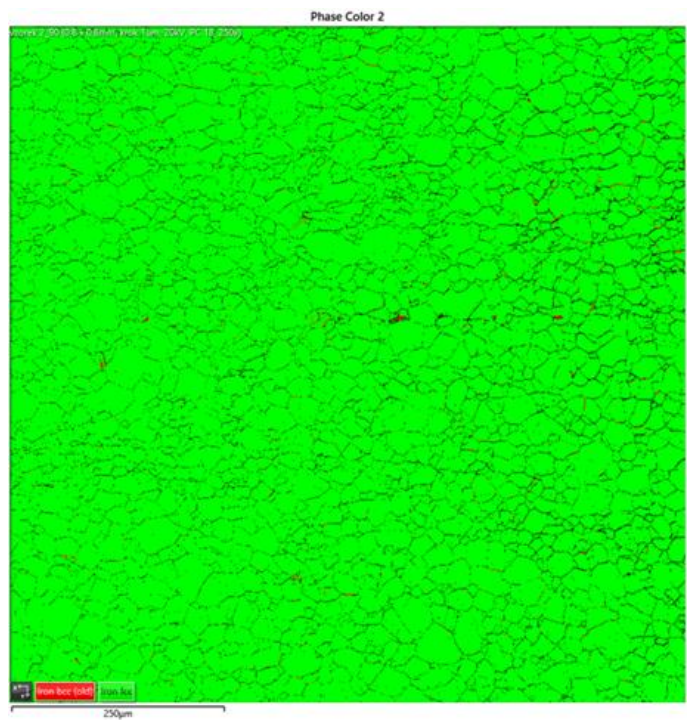

1.4301 - OK

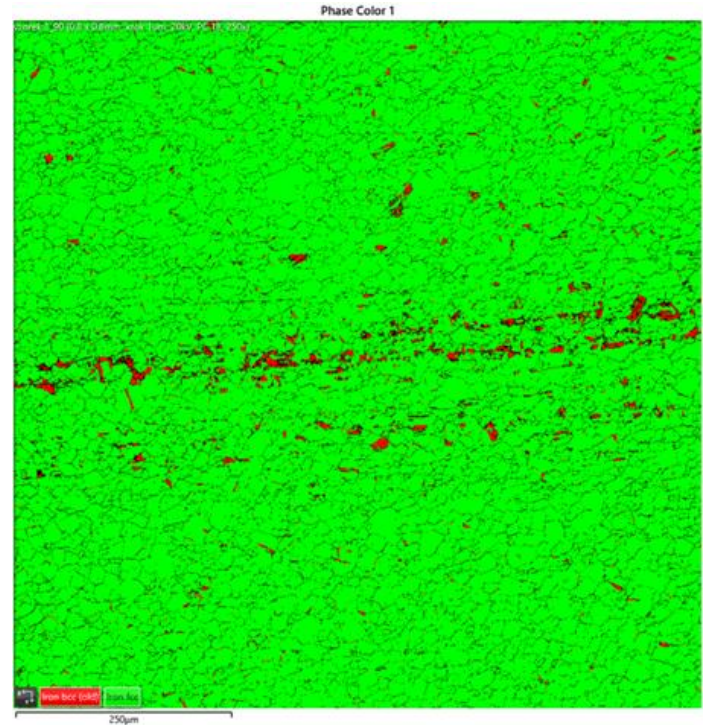

1.4301 - NOK

Figure 6 Structural analysis - ratio of the individual phases (austenite - green, ferrite - red) 


\section{CONCLUSION}

From the measured mechanical values is evident that both tested materials fulfil the prescribed mechanical values and mutual differences between these two tested materials are negligible from the metal forming point of view. From the performed hole expansion test, the different deformation behaviour of both tested materials under the given test is obvious. The material marked as 1.4301 - NOK achieved about $8 \%$ lower plastic properties compared to the material 1.4301 - OK. The higher cutting clearance, the better plastic properties of both materials, which can be explained by the decreasing hardening in the shear edge area. From the chemical composition analysis point of view is evident, that differences in the chemical composition of both tested materials are negligible and device Q4 Tasman identified both of them as material 1.4301. From the structural analysis is arising that shape and size of grains are practically identical for both tested materials - to be specific that differences in grain size between 1.4301 - NOK and 1.4301 - OK are negligible. On the other hand, as the problem should be taken into account portion of the austenitic and ferritic phases in the structure of both tested materials. In the case of material 1.4301 - OK, the structure consists exclusively of an austenitic phase with a trace amount of ferrite $(0.5 \%)$ homogeneously dispersed throughout the material volume. However, the material marked as 1.4301 - NOK has in the structure about $3 \%$ of ferrite that can be found in the shape of strips in the middle of material thickness. This inhomogeneity (to be specific - microscopic texture of ferrite) can probably cause the material tendency to crack when the cutting edge is plastically deformed. However, there should be performed another studies about such influence together especially with other materials.

\section{ACKNOWLEDGEMENTS}

This work was supported by the Student Grant Competition of the Technical University of Liberec under the project No. SGS-2019-5015 "Research and development for innovation of materials and production technologies with application potential in mechanical engineering".

\section{REFERENCES}

[1] DAVIES, G. Materials for Automobile Bodies. Oxford: Butterworth-Heinemann, 2012. ISBN 978-0-08-096979-4.

[2] BUNGE, H.-J., BANABIC, D., PÖHLANDT, K. Formability of metallic materials: plastic anisotropy, formability testing, forming limits. Berlin; London: Springer, 2011. ISBN 978-3-642-08750-9.

[3] KUHN, H., D. MEDLIN, ed. ASM HANDBOOK Volume 8 - Mechanical Testing and Evaluation. 10th ed. Materials Park: ASM International, 2000, p. 998. ISBN 0-87170-389-0

[4] NARAYANASAMY, R., NARAYANAN, C. S., PADMANABHAN, P., VENUGOPALAN, T. Effect of mechanical and fractographic properties on hole expandability of various automobile steels during hole expansion test. The International Journal of Advanced Manufacturing Technology. 2010, vol. 47, no. 1-4, pp. 365-380.

[5] PAUL, S. K. A critical review on hole expansion ratio. Materialia. [online]. 2020 [viewed: 2021-04-16]. Available from: https://doi.org/10.1016/j.mtla.2019.100566.

[6] HANCE, B. M. Practical Application of the Hole Expansion Test. SAE International Journal of Engines. 2017, vol. 10, no. 2, pp. 247-257.

[7] KEJZLAR, P., MACAJOVA, E., ŠVEC, M., VODIČKOVÁ, V. Využití kombinace energiově-disperzní analýzy a difrakce zpětně odražených elektronů pro strukturoskopii slitin na bázi Fe-Al-Zr. Jemná mechanika a optika (Fine Mechanics and Optics). 2013, vol. 58, no. 11-12, pp. 309-312. 